$10-5-2003$

\title{
Measurement of Anti-Cancer Agent Methoxyamine in Plasma by Tandem Mass Spectrometry with On-Line Sample Extraction
}

\author{
Shuming Yang \\ Cleveland State University \\ Lili Liu \\ Case Western Reserve University \\ Stanton L. Gerson \\ Case Western Reserve University \\ Yan Xu \\ Cleveland State University, y.xu@csuohio.edu
}

Follow this and additional works at: https://engagedscholarship.csuohio.edu/scichem_facpub

Part of the Analytical Chemistry Commons

How does access to this work benefit you? Let us know!

\section{Recommended Citation}

Yang, Shuming; Liu, Lili; Gerson, Stanton L.; and Xu, Yan, "Measurement of Anti-Cancer Agent Methoxyamine in Plasma by Tandem Mass Spectrometry with On-Line Sample Extraction" (2003). Chemistry Faculty Publications. 200.

https://engagedscholarship.csuohio.edu/scichem_facpub/200 


\title{
Measurement of anti-cancer agent methoxyamine in plasma by tandem mass spectrometry with on-line sample extraction
}

\author{
Shuming Yang Lili Liu Stanton L. Gerson Yan Xu
}

\section{Introduction}

Methoxyamine $\left(\mathrm{CH}_{3} \mathrm{ONH}_{2}\right)$ is a biochemical inhibitor of the base excision repair (BER) pathway [1-3]. It has been demonstrated that methoxyamine has the potential to be a new chemotherapeutic agent for treating cancers $[4,5]$ because it synergizes with alkylating agents such as temozolomide through its reaction with the aldehyde group at apurinic/ apyrimidinic (AP) site on the sugar-phosphate backbones of the cellular DNA [6,7]. The formation of DNA-methoxyamine adduct at the AP site interrupts the BER process, and is responsible for sustaining DNA damage induced by alkylating agent. This approach provides a new therapeutic strategy to overcome tumor resistance to alkylating agents. Currently, 
methoxyamine is chosen by the Rapid Access to Intervention Development (RAID) program of the National Cancer Institute as a potential new therapeutic agent for further investigation [8].

To study the pharmacology and toxicology of methoxyamine, an analytical method is desirable for the measurement of methoxyamine in plasma samples. Since methoxyamine is a small organic amine, it is very soluble in aqueous solution and plasma. Moreover, methoxyamine possesses neither chromophore for spectrophotometric detection nor enough mass sensitivity for mass spectrometric detection. It imposes a great difficulty for plasma sample preparation and detection. Although, it had been reported that methoxyamine could be detected by polarography [9], spectrophotometry [10], and HPLC-UV [11] methods. Due to the lack of specificity, none of these methods could be successfully applied to the measurement of methoxyamine in plasma. An extensive literature search revealed no publication in the field.

This paper describes the development and validation of a tandem mass spectrometry method for quantitative determination of methoxyamine in plasma samples. Methoxyamine together with the internal standard methoxyl-D3-amine was directly derivatized in plasma sample with a novel chemical agent 4-(N,N-diethylamino)benzaldehyde. The product solution was injected into an on-line column for analyte extraction. After the elution of extractives, the derivatized analytes were quantitated by positive-electrospray-ionization tandem mass spectrometry (ESI-MS-MS). The method developed has been used to analyze methoxyamine in plasma samples.

\section{Experimental}

\section{Chemicals and solutions}

Acetic acid, HPLC grade acetonitrile, 4-( $N, N$-diethylamino)benzaldehyde, formic acid, and trifluoroacetic acid were from Aldrich. Methoxyamine hydrochloride $\left(\mathrm{CH}_{3} \mathrm{ONH}_{2} \cdot \mathrm{HCl}\right)$ was from Sigma. Methoxyl-D3-amine hydrochloride $\left(\mathrm{CD}_{3} \mathrm{ONH}_{2} \cdot \mathrm{HCl}\right.$, lot no. G582P1) was from CDN Isotopes Inc. (Pointe-Claire, Que., Canada) and used as the internal standard (I.S.).
A stock solution $(10.0 \mathrm{mg} / \mathrm{ml})$ of methoxyamine hydrochloride $\left(\mathrm{CH}_{3} \mathrm{ONH}_{2} \cdot \mathrm{HCl}\right)$ and a stock solution $(10.0 \mathrm{mg} / \mathrm{ml})$ of methoxyl-D3-amine hydrochloride $\left(\mathrm{CD}_{3} \mathrm{ONH}_{2} . \mathrm{HCl}\right)$ were prepared by dissolving appropriate amount of each compound in a known volume of deionized water obtained from a NANOpure system (Barnstead, Dubuque, IA, USA). A stock solution $(175 \mathrm{mg} / \mathrm{ml})$ of 4 -( $N, N$-diethylamino)benzaldehyde was prepared by dissolving appropriate amount of the compound in a known volume of aqueous solution of acetic acid $\left(\mathrm{H}_{2} \mathrm{O}: \mathrm{CH}_{3} \mathrm{COOH}, 1: 1\right.$, v/v). The above stock solutions were stored at $4{ }^{\circ} \mathrm{C}$ when not in use.

A working solution $(5.00 \mu \mathrm{g} / \mathrm{ml})$ of methoxyamine $\left(\mathrm{CH}_{3} \mathrm{ONH}_{2}\right)$ was prepared by a two-step dilution $(1 / 100,8.88 / 100)$ of the methoxyamine hydrochloride stock solution with deionized water. A working solution $(60.0 \mathrm{ng} / \mathrm{ml})$ of methoxyl-D3-amine $\left(\mathrm{CD}_{3} \mathrm{ONH}_{2}\right)$ was prepared by a three-step dilution $(1 / 100,1 / 100$, $1.038 / 10)$ of the methoxyl-D3-amine hydrochloride stock solution with deionized water. A working solution $(10.0 \mathrm{mg} / \mathrm{ml})$ of 4 - $(\mathrm{N}, \mathrm{N}$-diethylamino)benzaldehyde was prepared by direct dilution of the stock solution with an aqueous solution of formic acid $\left(\mathrm{H}_{2} \mathrm{O}: \mathrm{HCOOH}, 2: 1\right.$, v/v).

\section{Preparations of plasma calibrators and controls}

Pooled human plasma from voluntary blood donors containing no detectable methoxyamine was obtained from the Case Western Reserve University Hospital and used as the blank plasma. Plasma methoxyamine calibrators $(1.00,2.50,5.00,10.0,25.0,50.0,125$, $250,500,1000 \mathrm{ng} / \mathrm{ml}$ ) were prepared by the serial dilution of $5.00 \mu \mathrm{g} / \mathrm{ml}$ methoxyamine working solution with the blank human plasma. Plasma controls (5.00, $50.0,500 \mathrm{ng} / \mathrm{ml}$ ) were prepared by the serial dilution of $5.00 \mu \mathrm{g} / \mathrm{ml}$ methoxylamine working solution with the blank human plasma. All plasma samples were placed on ice before the derivatization reaction, and stored at $-20^{\circ} \mathrm{C}$ when not in use.

\section{Derivatization of plasma methoxyamine}

The derivatization reaction between the plasma methoxyamine and 4-( $N, N$-diethylamino)benzaldehyde took place in a $0.65 \mathrm{ml} \mathrm{Costar}{ }^{\circledR}$ microcentrifuge tube (cat. no. 3208) from Corning Incorporated 
(Corning, NY, USA). Fifty microliters of $\mathrm{H}_{2} \mathrm{O}$ and $50.0 \mu \mathrm{l} \quad 60.0 \mathrm{ng} / \mathrm{ml} \quad \mathrm{CD}_{3} \mathrm{ONH}_{2}$ (internal standard) were first added to $150 \mu \mathrm{l}$ plasma sample containing $\mathrm{CH}_{3} \mathrm{ONH}_{2}$. After mixing, $50.0 \mu \mathrm{l} 4$ - $(N, N$-diethylamino)benzaldehyde solution $(10.0 \mathrm{mg} / \mathrm{ml})$ was added to the mixture. The mixture was then vortexed, heated at $80^{\circ} \mathrm{C}$ for $1 \mathrm{~h}$ in a dry bath incubator (Fisher Scientific, Pittsburgh, PA, USA), and centrifuged for $5 \mathrm{~min}$ in a C-1200 mini centrifuge (National Labnet Co., Woodbridge, NJ, USA) before subjected to the instrumental analysis.

\section{Recovery studies}

To assess the recovery of plasma methoxylamine under different sample storage times and temperatures, $100 \mathrm{ng} / \mathrm{ml}$ methoxyamine plasma sample was prepared by the dilution of methoxyamine working solution $(5.00 \mu \mathrm{g} / \mathrm{ml})$ with the blank human plasma. Aliquots of plasma sample $(150 \mu \mathrm{l}$ each) were pipetted into $\operatorname{Costar}^{\circledR}$ microcentrifuge tubes and kept at 24,4 , and $-20^{\circ} \mathrm{C}$, respectively. At different time intervals, these samples were processed and analyzed. The derivatization of plasma methoxyamine was carried out at $24^{\circ} \mathrm{C}$ (i.e. room temperature) and $80^{\circ} \mathrm{C}$.

To validate the analytical procedures, plasma methoxyamine standards and aqueous methoxyamine references $(5.00,50.0,500 \mathrm{ng} / \mathrm{ml})$ were prepared separately by the serial dilution of methoxyamine working solution $(5.00 \mu \mathrm{g} / \mathrm{ml})$ with the blank human plasma and deionized water. After the derivatization reaction at $80^{\circ} \mathrm{C}$ for $1 \mathrm{~h}$, the samples were analyzed. The relative recovery of methoxyamine was determined by comparing the mean-peak-area ratio of methoxyamine to the internal standard in the plasma standards to the mean-peak-area ratio of methoxyamine to the internal standard in the aqueous references.

\section{Pharmacokinetic study}

Plasma methoxyamine elimination kinetics was determined using male CD1 mice from the Jackson Laboratory (Bar Harbor, ME, USA). The mice (four mice per group) were randomly treated with single bolus intraperitoneal injection of 2,5 and $20 \mathrm{mg}$ methoxyamine hydrochloride $\left(\mathrm{CH}_{3} \mathrm{ONH}_{2} \cdot \mathrm{HCl}\right) / \mathrm{kg}$ mouse. Blood samples were collected into heparinized tubes at $1,2.5,5,10,20,30$, and $60 \mathrm{~min}$ after the injection using a needle and syringe via an approach to the heart under ether anesthesia. The blood samples were placed on ice and centrifuged within $2 \mathrm{~h}$ of the collections. The resultant plasma samples were stored at $-20^{\circ} \mathrm{C}$ prior to the analysis. In this work, the pooled mouse plasma from mice without the injection of methoxyamine hydrochloride was used as the blank mouse plasma.

\section{Instrumentation}

The instrumentation system consisted of an HP1100 pump (Hewlett-Packard, Palo Alto, CA, USA), an HP1100 autosampler, a stainless steel in-line filter $(0.5 \mu \mathrm{m}$ pore, $0.23 \mu \mathrm{l}$ dead volume, Upchurch Scientific, Oak Harbor, WA, USA), an Oasis ${ }^{\circledR}$ HLB extraction column $(2.1 \mathrm{~mm} \times 20 \mathrm{~mm}$, Waters, Milford, MA, USA), a Rheodyne 7000 two-position 6-port switching valve (Supelco, Bellefonte, PA, USA), a stainless steel splitting tee $(1 / 16$ in. $\times 0.25 \mathrm{~mm}$, Valco, Houston, TX, USA), and a Quattro II triple quadrupole mass spectrometer (Micromass, Manchester, UK).

The fluidic connection of the system is shown in Fig. 1. High-pressure polyether ether ketone (PEEK) tubing (0.0625 in. o.d.) was used. Except the connection between the splitting tee and the MS detector (0.005 in. i.d.), all other connections used 0.01 in. i.d. tubing. At the position 1 of the switching valve, the extraction solvent carried the plasma sample from the autosampler to the extraction column where the analytes were retained and the plasma matrix was excluded to the waste. At the position 2 of the switching valve, the elution solution eluted the retained compounds from the extraction column, and carried them to the splitting tee where the flow was diverted to the ESI-MS-MS detector and the waste with a split ratio of $1: 5$. The smaller flow (ca. $100 \mu \mathrm{l} / \mathrm{min}$ ) went to the MS detector and the larger one to the waste.

\section{On-line sample preparation}

On-line extraction of methoxyamine and internal standard from plasma were performed on an Oasis ${ }^{\circledR}$ HLB extraction column. Prior to the analysis, the extraction column was first equilibrated with the extraction solvent $\left(\mathrm{H}_{2} \mathrm{O}\right)$ at a flow rate of $2.0 \mathrm{ml} / \mathrm{min}$ for 


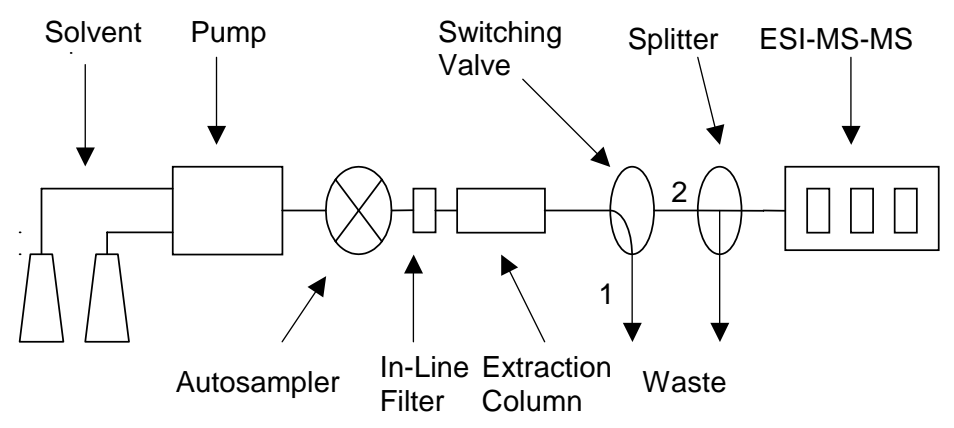

Fig. 1. The block diagram of the instrumentation system.

about $1.0 \mathrm{~min}$ with the switching valve on the position 1 (Fig. 1). During the analyses, $10 \mu l$ derivatized plasma sample was injected by the autosampler and carried onto the extraction column by the extraction solvent $\left(\mathrm{H}_{2} \mathrm{O}\right)$ at a flow rate of $2.0 \mathrm{ml} / \mathrm{min}$. The plasma matrix was washed away by the extraction solvent to the waste, and the analytes of interest were extracted by the column. At $1 \mathrm{~min}$ after the sample injection, the switching valve was turned to the position 2 . Simultaneously, the extraction solvent was switched to the elution solution $\left(95 \%\right.$ acetonitrile $\left.+5 \% \mathrm{H}_{2} \mathrm{O}\right)$ at a flow rate of $0.6 \mathrm{ml} / \mathrm{min}$, which initiated the elution of analytes from the extraction column. At 3 min after the elution, the switching valve was turned back to the position 1 . The column was continuously washed with the elution solution at a flow rate of $2.0 \mathrm{ml} / \mathrm{min}$ for another $0.5 \mathrm{~min}$. Finally, the extraction column was equilibrated with the extraction solvent at a flow rate of $2.0 \mathrm{ml} / \mathrm{min}$ for $0.5 \mathrm{~min}$ before the next sample injection. The total run time was about $5.0 \mathrm{~min}$ per sample.

\section{Mass spectrometric detection}

The Quattro II triple quadrupole mass spectrometer was operated under the positive-electrospray-ionization mode (ESI+). It was tuned by infusion of a reaction mixture of methoxyamine and methoxyl-D3-amine $(1.25 \mu \mathrm{g} / \mathrm{ml}$ each) with 4 -( $N, N$-diethylamino)benzaldehyde $(2.5 \mathrm{mg} / \mathrm{ml})$ in $50 \%$ acetonitrile $+40 \%$ $\mathrm{H}_{2} \mathrm{O}+10 \%$ formic acid (which was needed for the derivatization reaction) at a flow rate of $3 \mu \mathrm{l} / \mathrm{min}$ with a syringe pump (Harvard Apparatus, South Natick, MA, USA). The optimized ionization conditions were: nitrogen sheath and desolvation gas at 10 and
$350 \mathrm{l} / \mathrm{h}$, capillary at $3.5 \mathrm{kV}, \mathrm{HV}$ lens at $0.5 \mathrm{kV}$, cone at $34 \mathrm{~V}$, skimmer at $1.5 \mathrm{~V}$, RF lens at $0.2 \mathrm{~V}$, ion source temperature at $70^{\circ} \mathrm{C}$, ion energy at $1.2 \mathrm{~V}$, low- and high-mass resolution at 15 , and mutliplier at $650 \mathrm{~V}$. Full-scan spectra were acquired in the continuum mode at a scan rate $500 \mathrm{amu} / \mathrm{s}$.

Multiple reaction monitoring (MRM) data were acquired with the following parameters: $\mathrm{m} / \mathrm{z} 207>$ 149 for the derivatization product of methoxylamine, $m / z 210>149$ for the derivatization product of methoxyl-D3-amine, argon collision gas at 2.0-2.5 $\mu$ bar, cone at $34 \mathrm{~V}$, collision energy at $20 \mathrm{~V}$ for each analyte, low- and high-mass resolution at 15 for both quadrupole 1 and 3 , dwell time at $0.3 \mathrm{~s}$, and the inter-scan delay at $0.03 \mathrm{~s}$. The ionization parameters were the same as those described previously.

\section{Data analysis}

Data acquisition and peak integration were done with Micromass Masslynx software (Version 3.4). The peak-area ratios of the derivatized methoxyamine to the derivatized internal standard were plotted against the methoxyamine concentration for the regression equation. The plasma methoxyamine concentrations of the unknown samples were determined by the regression equation after obtaining the peak-area ratios from their mass chromatograms.

Non-compartmental method was used to analyze the data of pharmacokinetic study using WinNonLin (Version 4.0.1) (Pharsight Corp., Mountain View, CA, USA). The area under the curve (AUC) was determined by the linear trapezoidal rule, and the half-life $\left(T_{1 / 2}\right)$ was estimated from the terminal portion of the curve. 


\section{Results and discussion}

\section{Derivatization of methoxyamine}

Methoxyamine $(\mathrm{MM}=47.06)$ is a small basic molecule, which has a $\mathrm{p} K_{\mathrm{b}}$ of 9.40 in aqueous solution at $25^{\circ} \mathrm{C}$ [12]. In plasma or aqueous solution $(\mathrm{pH}<$ 9.4), methoxyamine readily exists in its protonated form $\left(\mathrm{CH}_{3} \mathrm{ONH}_{3}{ }^{+}\right)$. Due to its strong hydrophilicity, it is difficult to separate methoxyamine directly from the other plasma components by liquid-liquid extraction (LLE) or solid-phase extraction (SPE). Moreover, methoxyamine does not possess chromophore for spectrophotometric detection or have enough mass sensitivity and selectivity for mass spectrometric detection.

To overcome the obstacles of measuring methoxyamine in plasma, we had chosen the method of chemical derivatization. The reasons for this approach were two folds. Firstly, we could increase the hydrophobicity of methoxyamine by reacting with a chemical derivatizing agent, so that the derivatized analyte could be extracted from plasma samples with LLE or SPE. Secondly, after derivatization, we could easily detect the derivatized analyte using one of the following techniques: LC with UV detection, LC with fluorescence detection, GC-MS, LC-MS, and MS-MS.

It has been previously reported that $\left[{ }^{14} \mathrm{C}\right]$ methoxyamine can be used for the quantitative measurement of AP sites on the sugar-phosphate backbones of the DNA through its reaction with the aldehyde group on the AP sites [13]. Therefore, it is a reasonable deduction that a successful methoxyamine derivatizing agent may possess an aldehyde function group. Furthermore, the derivatizing agent should be more hydrophobic than methoxyamine so that its product can partition in the organic phase during sample extraction, and yet be soluble enough in aqueous solution to insure its reaction with methoxyamine in plasma matrices.

In this work, several chemical derivatization agents including fluorescamine, 1-naphthaldehyde, 4-( N,Ndimethylamino)benzaldehyde and 4-( $N, N$-diethylamino)benzaldehyde have been tested for this application. Due to its solublity, derivatization efficiency and analytical recovery, 4-( $N, N$-diethylamino)benzaldehyde was chosen for the analytical method development in this work. Under the acidic conditions, the derivatization reaction between 4-( $N, N$-diethylamino)benzaldehyde and methoxyamine (so as internal standard methoxyl-D3-amine) proceeds very quickly and smoothly in aqueous solution at room temperature (Fig. 2). To assure a complete reaction, the amount of 4 -( $N, N$-diethylamino)benzaldehyde used was stoichiometrically a 1000 -fold higher than the amount of methoxyamine in the reaction.

In this work, trifluoroacetic acid, acetic acid, and formic acid were tested as the proton donor for the derivatization reaction. It was found that all these organic acids worked well in aqueous solutions. However, trifluoroacetic acid caused immediate protein precipitation in plasma samples, and acetic acid
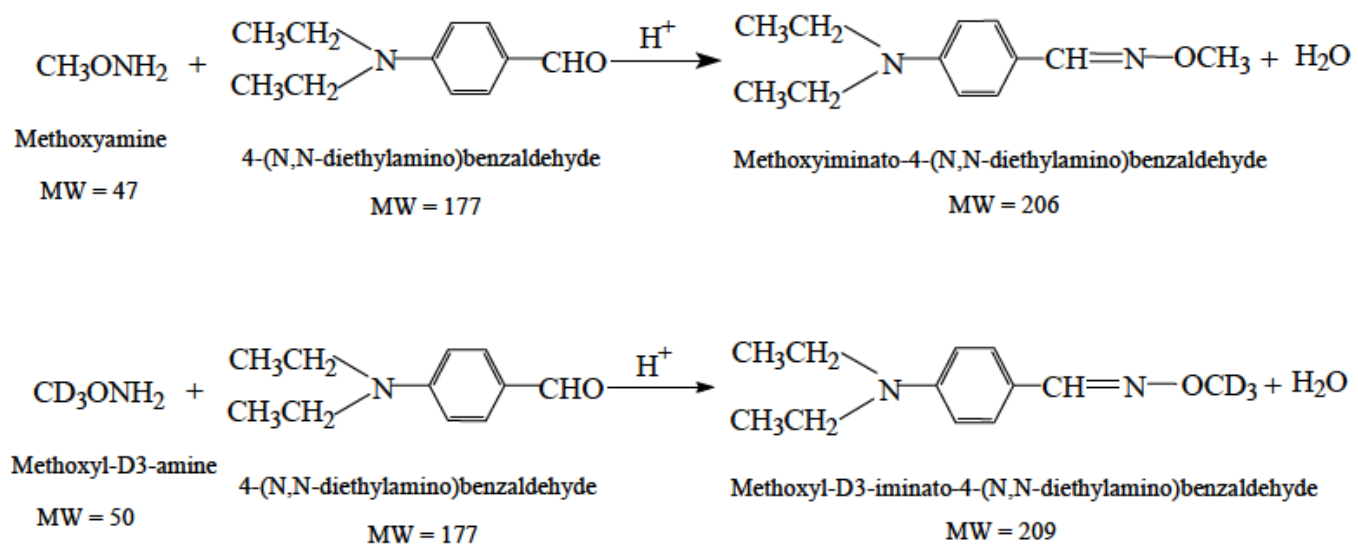

Fig. 2. The derivatization reactions of $4-(N, N$-diethylamino)benzaldehyde with methoxyamine and internal standard methoxyl-D3-amine. 
gelatinized plasma even at the concentration as low as $5.6 \%(\mathrm{v} / \mathrm{v})$. Only formic acid did not have such shortcomings. Our studies indicated that the reaction proceeds well over a formic acid concentration range of 5.6-39\% (v/v). Compared to a lower formic acid concentration, a higher concentration resulted in higher viscosity of the reaction mixture. Therefore, a formic acid concentration of $5.6 \%(\mathrm{v} / \mathrm{v})$ was used for the analytical procedures.

The recovery of plasma methoxyamine was investigated under different sample storage times and temperatures. After spiking methoxyamine into the pooled human plasma, the plasma samples were stored at 24 , 4 and $-20^{\circ} \mathrm{C}$ for $0,2,4,6,10$ and $24 \mathrm{~h}$ prior to the derivatization reaction and the instrumental analysis. Fig. 3 showed the recoveries of methoxyamine using the derivatization procedure as described in Section 2 at the room temperature and $80^{\circ} \mathrm{C}$. If the derivatiza-
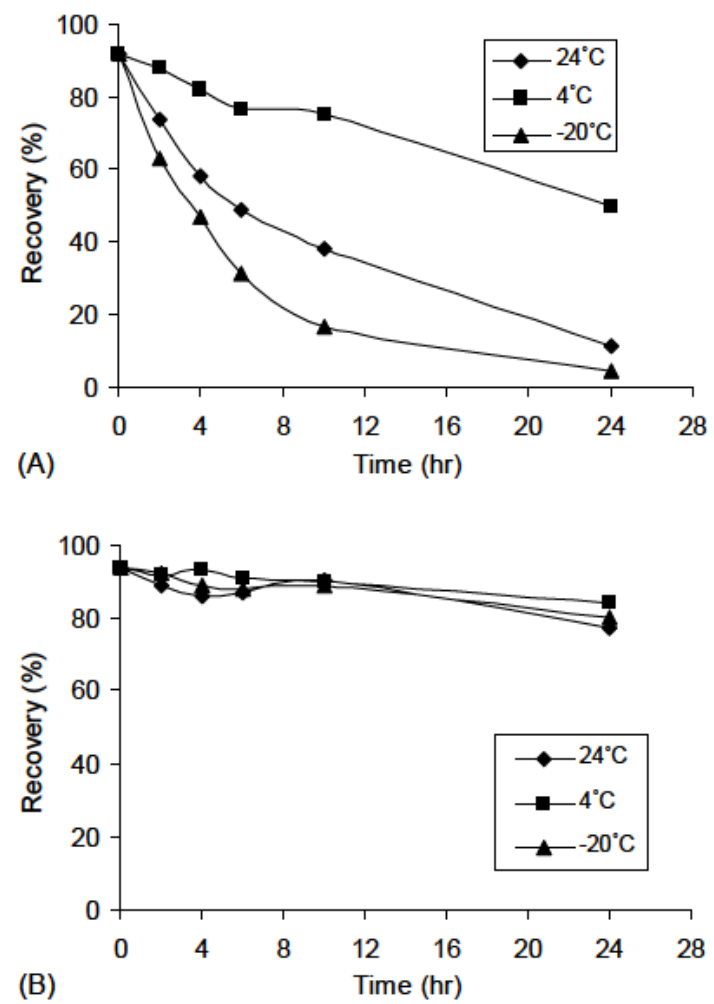

Fig. 3. The effect of storage time and temperature on the recovery of methoxyamine in human plasma: (A) the derivatization reaction was carried out at the room temperature, $24^{\circ} \mathrm{C}$ and (B) the derivatization reaction was carried out at $80^{\circ} \mathrm{C}$ for $1 \mathrm{~h}$. Plasma sample: the pooled human plasma spiked with $100 \mathrm{ng} / \mathrm{ml}$ methoxyamine. tion reaction was carried out at the room temperature, the recovery of methoxyamine decreased with both the increase of storage time and the decrease of storage temperature (Fig. 3A); whereas if the derivatization reaction was carried out at $80^{\circ} \mathrm{C}$, the recovery of methoxyamine was $80 \%$ or greater regardless of the storage temperatures and times (Fig. 3B).

One reasonable explanation for these observations was that the derivatizing agent 4 -( $N, N$-diethylamino)benzaldehyde reacted only with the unbound methoxyamine in plasma. In plasma samples, methoxyamine interacted with the plasma proteins and formed protein-bound methoxyamine. The longer the interaction between methoxyamine and plasma proteins, the larger amount of methoxyamine bound to the proteins before the system reached equilibrium. Furthermore, as the temperature decreased the amount of methoxyamine bound to the proteins would increase because the interaction between methoxyamine and plasma protein was exothermic in nature. At $80^{\circ} \mathrm{C}$, the release of methoxyamine by its binding proteins was both thermodynamics- and kinetics-favored process; therefore, the recovery of methoxyamine was high.

Since the binding of methoxyamine to plasma proteins is reversible, the reaction between $4-(N, N-$ diethylamino)benzaldehyde and methoxyamine should favor the release of methoxyamine from its binding proteins according to Le Chatelier's principle [14]. Our experiments indicated that the recovery of methoxyamine increased with the increase of the reaction time between 4-( $N, N$-diethylamino) benzaldehyde and methoxyamine even at the room temperature. However, it needs tens of hours for a satisfactory recovery if the derivatization reaction takes place at the room temperature. In the analytical procedures, the derivatization reaction was performed at $80^{\circ} \mathrm{C}$ for $1 \mathrm{~h}$ to secure a high recovery of methoxyamine from plasma samples.

\section{Mass spectrometric detection}

In this work, the reactants and products were more easily protonated than deprotonated in the electrospray-ionization process; therefore, the positive ESI-MS mode was used for analyte identification. The full-scan mass spectra over the $\mathrm{m} / \mathrm{z}$ ratio of $45-230$ indicated that methoxyamine and methoxyl-D3-amine produced quasi-molecular ions at $\mathrm{m} / \mathrm{z} 48$ and 51 
(A)

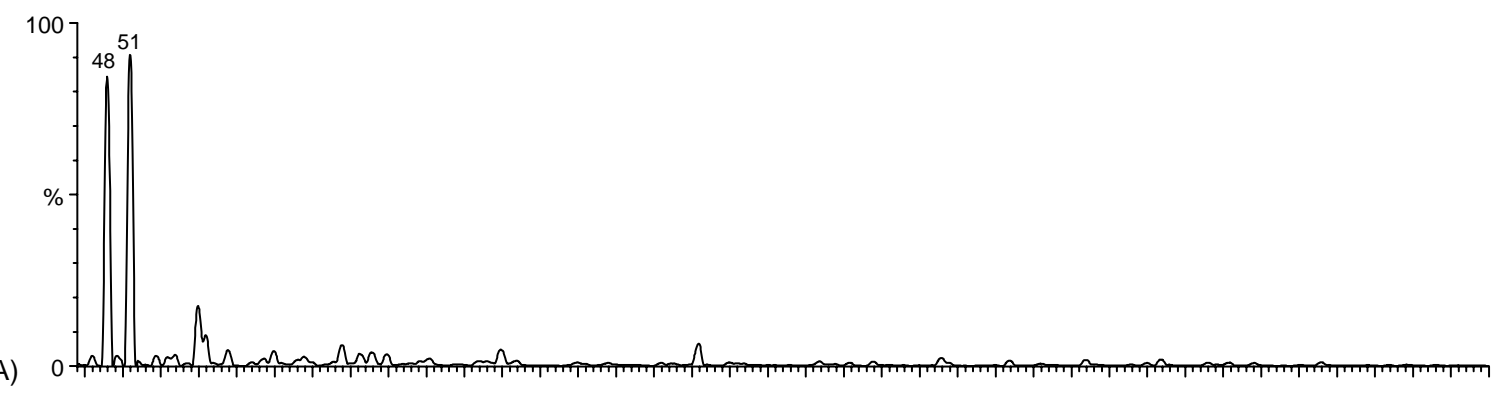

(B)

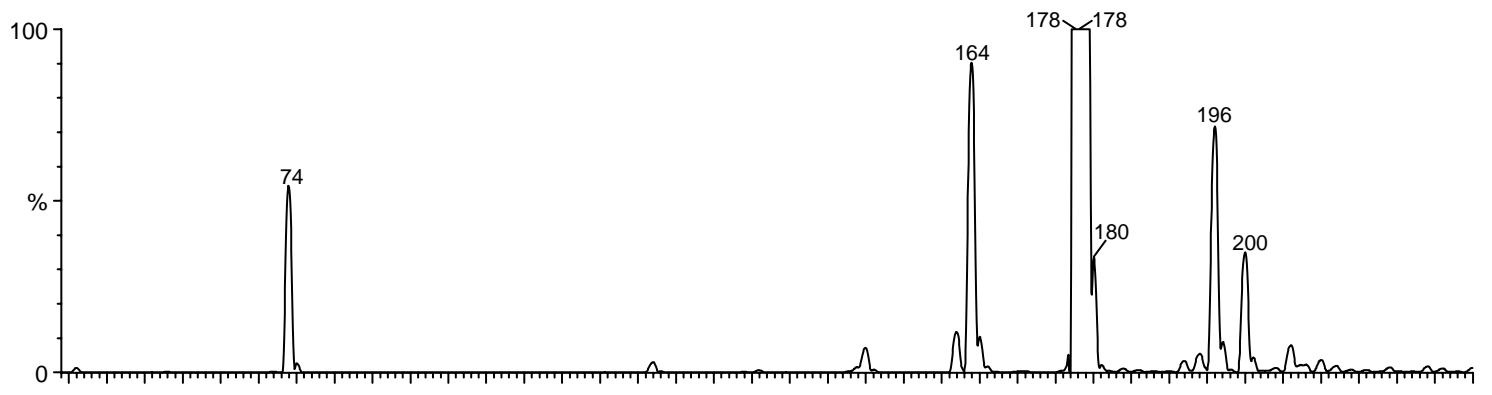

(C)

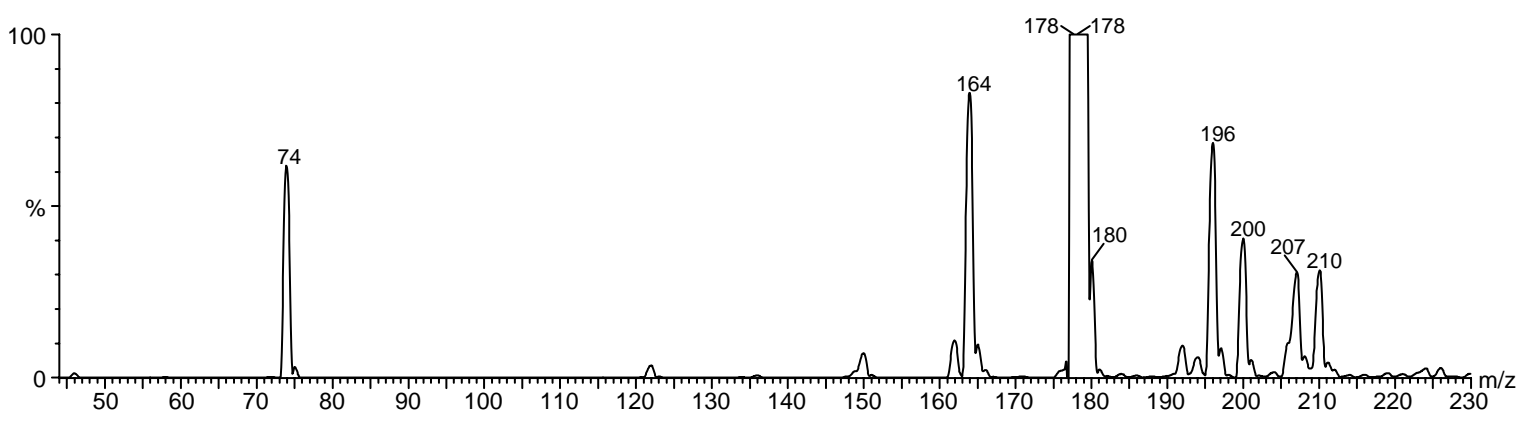

Fig. 4. The mass spectra of the reactants and products of the derivatization reactions: (A) $1.25 \mu \mathrm{g} / \mathrm{ml}$ methoxyamine and methoxyl-D3-amine in $50 \%$ acetonitrile $+0.3 \% \mathrm{HCOOH}$; (B) $2.5 \mathrm{mg} / \mathrm{ml} 4$ - $(\mathrm{N}, \mathrm{N}$-diethylamino)benzaldehyde in $50 \%$ acetonitrile $+10 \%$ formic acid and $(\mathrm{C})$ the $1: 1$ mixture of $(\mathrm{A})$ and $(\mathrm{B})$ at the room temperature.

(Fig. 4A), 4-( $N, N$-diethylamino)benzaldehyde at $\mathrm{m} / \mathrm{z}$ 178 (Fig. 4B), and the products of the derivatization reactions at $\mathrm{m} / \mathrm{z} 207$ and 210 (Fig. 4C). The positive ESI-MS-MS mode was used for both the structure elucidation of the products of derivatization reactions by selecting parent ions at $\mathrm{m} / \mathrm{z}, 207$ and 210 and monitoring their daughter ions over the $\mathrm{m} / \mathrm{z}$ ratio of 100-230 (Fig. 5), and the quantitative measurement of the derivatized analytes $(\mathrm{m} / \mathrm{z}$ $207>149$ for methoxyamine, and $m / z 210>149$ for methoxyl-D3-amine). Although many endogenous compounds in plasma samples coeluted with the derivatized analytes, the quantitative analysis by ESI-MS-MS showed no interference to the deriva- tized analytes. Therefore, it required no analytical separation column.

\section{Structure elucidation}

It was clearly identified in Fig. 4 that there were two quasi-molecular ions at $\mathrm{m} / \mathrm{z}, 207$ and 210 in the reaction mixture, which matched perfectly with the $\mathrm{H}^{+}$ adducts of the expected products of methoxyamine $(\mathrm{m} / \mathrm{z}, 207)$ and methoxyl-D3-amine $(\mathrm{m} / \mathrm{z} 210)$. Furthermore, the conversion efficiency of the derivatization reaction could be revealed by the complete disappearance of the mass peaks of methoxyamine $(\mathrm{m} / \mathrm{z}, 48)$ and methoxyl-D3-amine $(\mathrm{m} / \mathrm{z}, 51)$. 


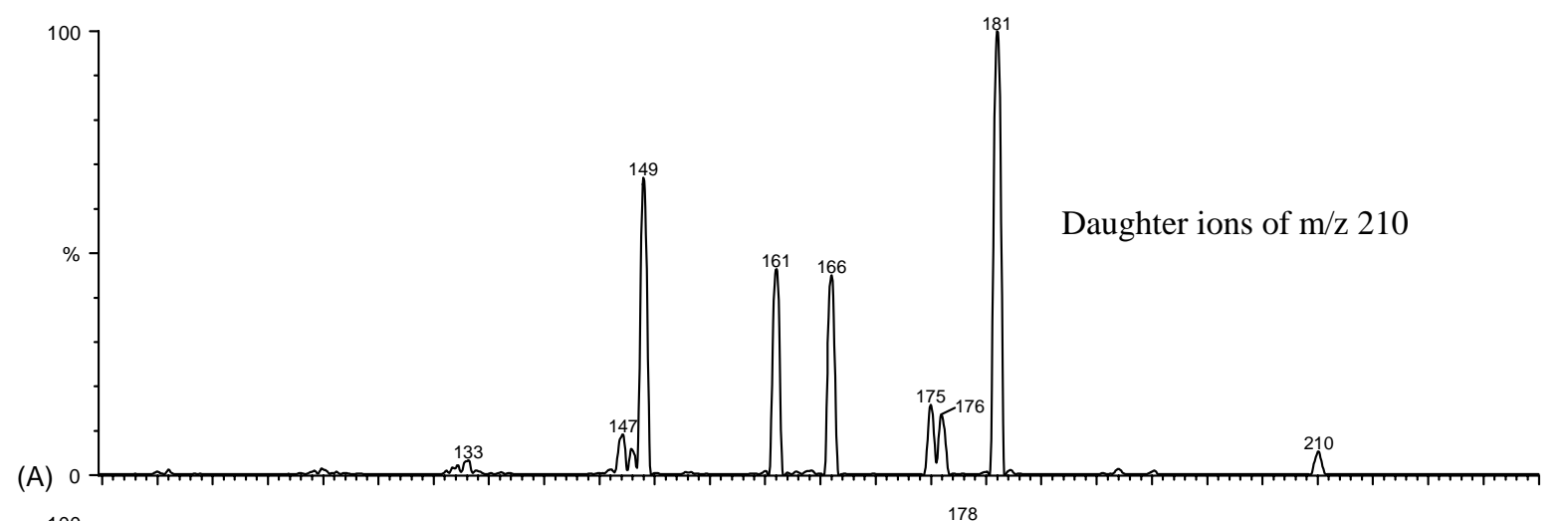

(B)

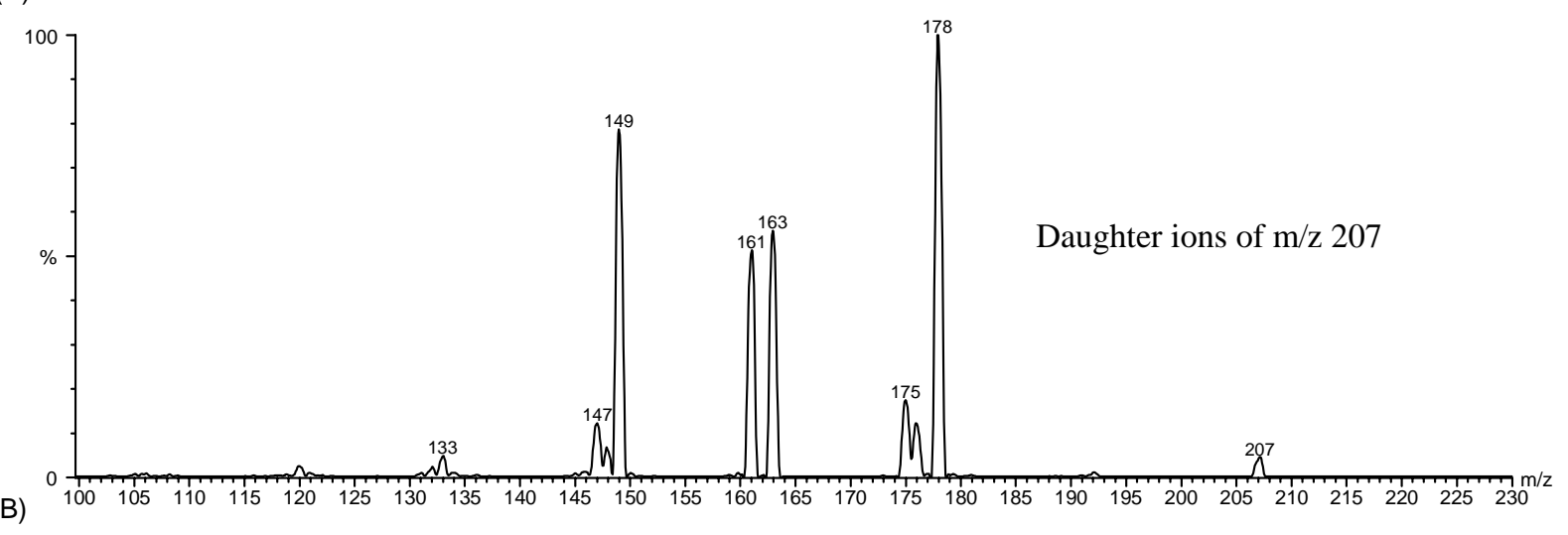

Fig. 5. The mass spectra of fragments ions from the products of the derivatization reactions. The daughter ions of peaks $(\mathrm{m} / z 210$ and 207) in Fig. 4C.

To elucidate the structures of the products of the derivatization reactions, the fragmentation of the product peaks $(\mathrm{m} / \mathrm{z} 207$ and 210) was carried out by colliding with argon gas in the collision cell inside of the mass spectrometer. The mass spectra of daughter ions (fragments of the derivatized analytes) were acquired by the ESI-MS-MS (Fig. 5). By the comparison of the daughter ions spectra of the two reaction products, the assignments of the fragment ions could be made. Fig. 6 shows the assignments of five major fragments of the expected products, methoxyiminato-4-( $N, N$-diethylamino)benzaldehyde and methoxyl-D3-iminato-4-( $N, N$-diethylamino)benzaldehyde.

\section{On-line sample preparation}

Plasma sample preparation is often considered as the bottleneck in drug analyses. To increase the sample throughput, a Waters Oasis ${ }^{\circledR}$ HLB extraction column $(2.1 \mathrm{~mm} \times 20 \mathrm{~mm})$ was used for on-line sample preparation. According to its manufacturer, the column was packed with a macroporous copolymer of divinylbenzene and $N$-vinylpyrrolidone, which has dual retention capability to both polar and non-polar compounds. This type of column had been proven to be effective for plasma sample preparations in our previous works $[15,16]$. In this work, it was found that the products of derivatization reaction, methoxyiminato-4-( $N, N$-diethylamino) benzaldehyde and methoxyl-D3-iminato-4-( $N, N$-diethylamino)benzaldehyde retained strongly on the extraction column, whereas the plasma proteins showed no sign of retention when $\mathrm{H}_{2} \mathrm{O}$ was used as the loading and washing solvent. With the use of the in-line filter and the after-use storage in $50 \% \mathrm{CH}_{3} \mathrm{CN}$ aqueous solution, the numbers of extraction performed by each column were greater than 300 times.

The effect of flow rate of the sample extraction step on the recovery of analytes was investigated. The data 


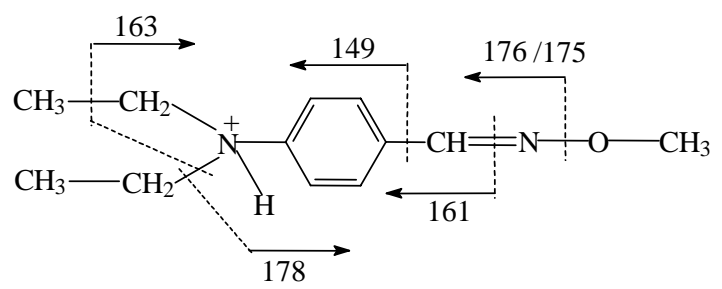

Methoxyiminato-4-(N,N-diethylamino)benzaldehyde

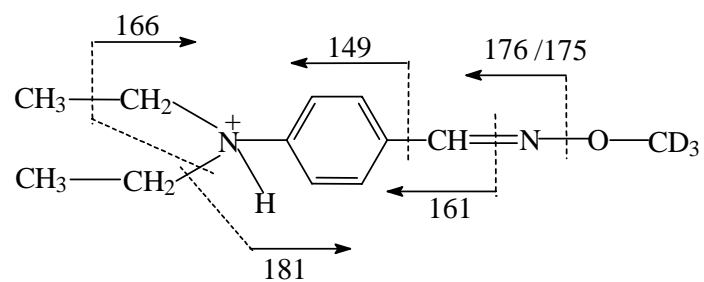

Methoxyl-D3-iminato-4-(N,N-diethylamino)benzaldehyde

Fig. 6. The assignments of five major fragments of the derivatized analytes, methoxyiminato-4-( $N, N$-diethylamino)benzaldehyde and methoxyl-D3-iminato-4-( $N, N$-diethylamino)benzaldehyde.

indicated there was no significant change in the analyte recovery in the flow rate range of $0.5-3.0 \mathrm{ml} / \mathrm{min}$. Upon the consideration of sample throughput and column pressure, a flow rate of $2.0 \mathrm{ml} / \mathrm{min}$ was chosen in the analytical procedures for sample extraction.

The elution of the derivatized analytes was largely affected by the composition of mobile phase. It was found that acetonitrile was a better organic solvent than methanol in the terms of peak shape, retention time, and signal response. The higher the percentage of acetonitrile, the shorter was the retention time of the derivatized analytes. In this work, an optimized composition of $95 \% \mathrm{CH}_{3} \mathrm{CN}+5 \% \mathrm{H}_{2} \mathrm{O}$ was used as the elution solution. It was worth noting that the addition of volatile acid (i.e. formic acid, acetic acid, or trifluoroacetic acid) at the concentration ranged $0.05-4 \%$ to the elution solution could cause dramatic reduction of the analyte retention time due to the weakened interaction between the protonated analyte and the packing material in the extraction column, and resulted in variations on the analyte recovery.

The flow rate of elution affects the analyte concentration at the outlet of the extraction column. Since ESI-MS is a concentration-dependent detector, the flow rate of elution can affect peak shape and intensity in a mass chromatogram. It was found that the peak width became narrower with the increase of flow rate (Fig. 7A). At the low flow rate, the peak height was large at first. As the flow rate increased, the peak height reached its maximum and declined dramatically (Fig. 7B). In this work, an elution flow rate of $0.6 \mathrm{ml} / \mathrm{min}$ was chosen for the analytical procedures, which provided the optimum detection sensitivity and adequate elution time. At this flow rate, the actual fluid entering the mass spectrometer was about $100 \mu \mathrm{l} / \mathrm{min}$ after a 1:5 ratio of post-column splitting.

\section{Specificity}

Methoxyl-D3-amine, a deuterated methoxyamine, was used as the internal standard for the measurement of methoxyamine in plasma samples. Plasma methoxyamine together with methoxyl-D3-amine reacted with the derivatizing agent 4 - $(N, N$-diethylamino)benzaldehyde. The products of the derivatization reaction, methoxyiminato-4-( $N, N$-diethylamino)benzaldehyde and methoxyl-D3-iminato-4-( $N, N$-diethylamino)benzaldehyde were detected by ESI-MS-MS. The quantitation of plasma methoxyamine was carried
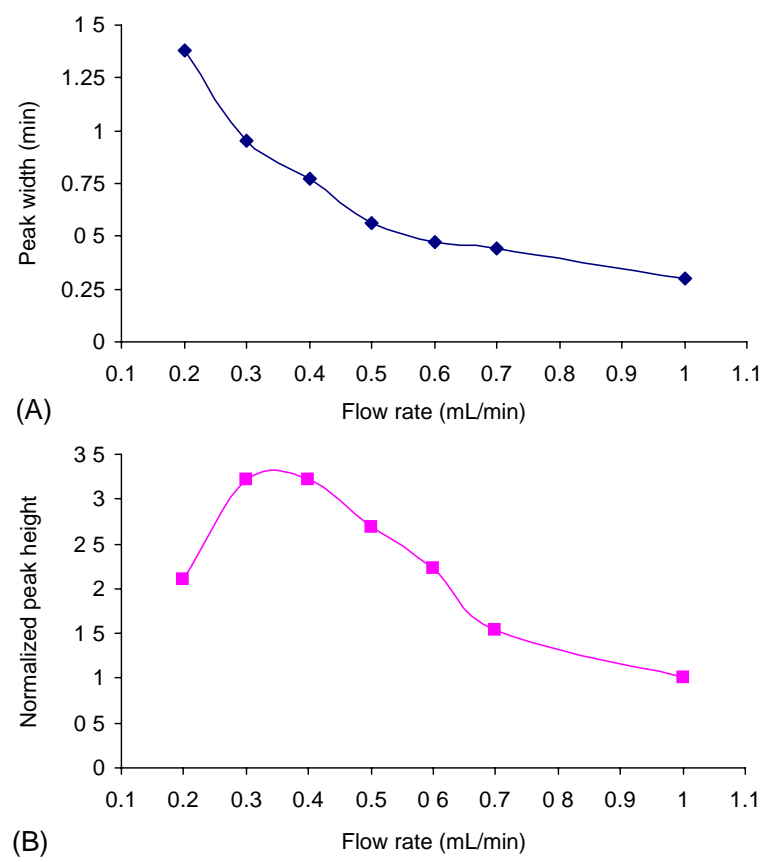

Fig. 7. The effect of elution flow rate on the peak width and peak height. The peak height was normalized by the peak height at the flow rate of $1.00 \mathrm{ml} / \mathrm{min}$. Plasma sample: the pooled human plasma spiked with $100 \mathrm{ng} / \mathrm{ml}$ methoxyamine. 

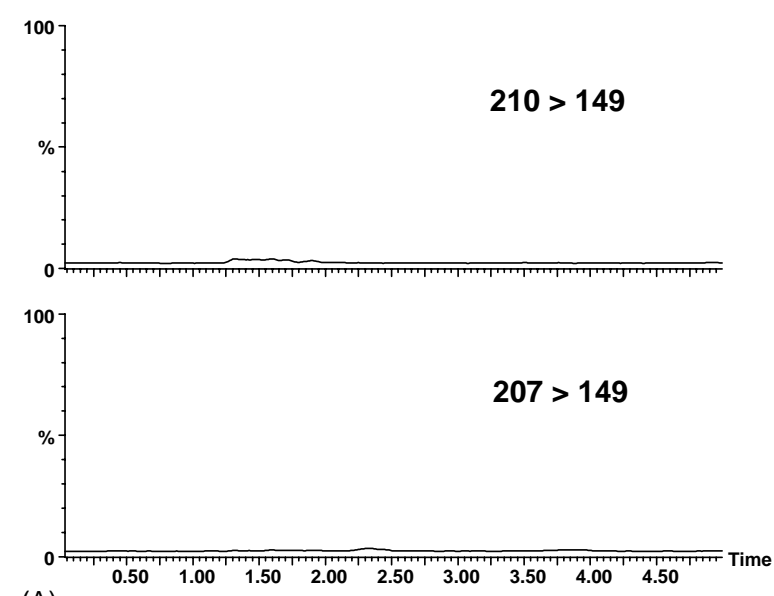

(A)
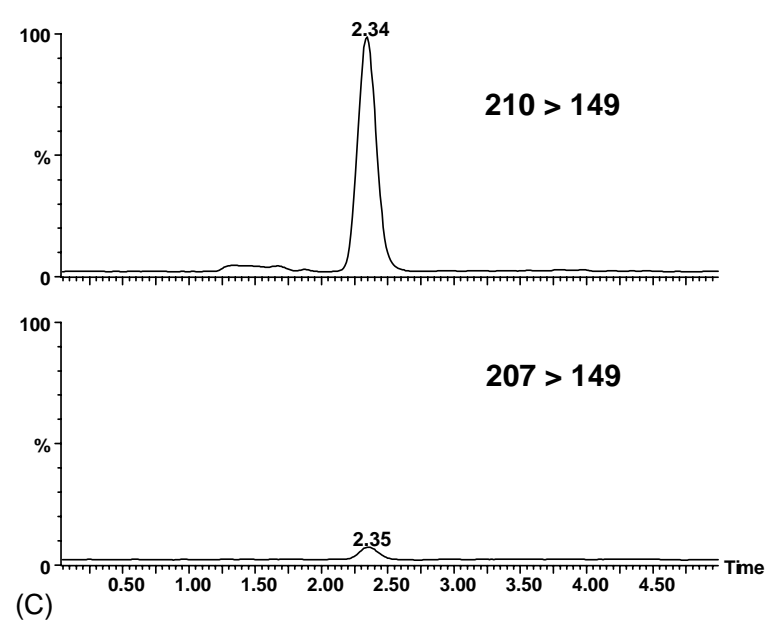
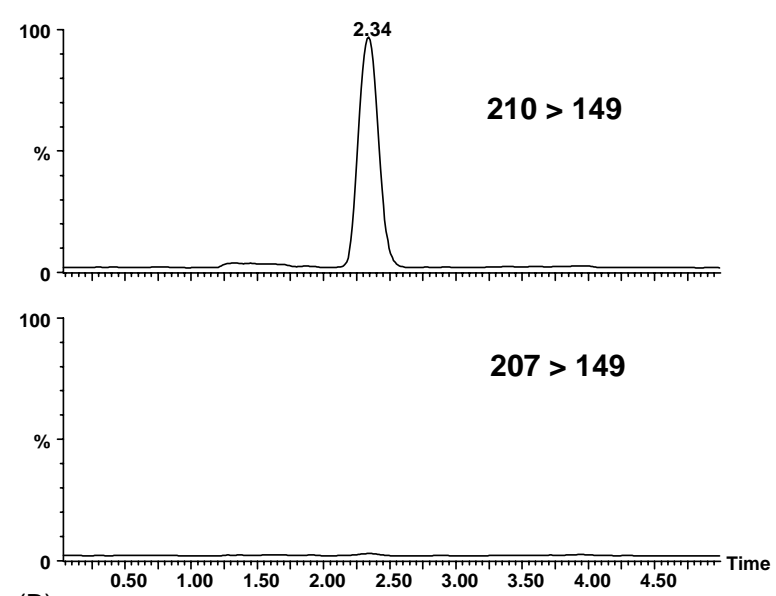

(B)
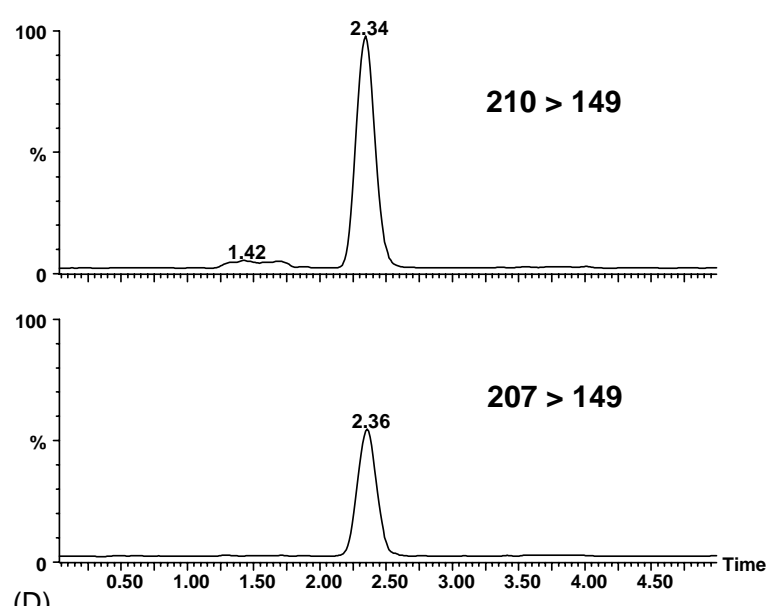

(D)

Fig. 8. The representative mass chromatograms of human plasma samples: (A) the pooled human plasma without I.S. methoxyl-D3-amine; (B) the pooled human plasma with I.S.; (C) $1.00 \mathrm{ng} / \mathrm{ml}$ plasma methoxyamine calibrator with I.S. and (D) $10.0 \mathrm{ng} / \mathrm{ml} \mathrm{plasma}$ methoxyamine calibrator with I.S.

out by monitoring one of the major fragments of methoxyiminato-4-( $N, N$-diethylamino)benzaldehyde $(\mathrm{m} / z 207>149)$ together with that of methoxyl-D3-iminato-4-( $N, N$-diethylamino)benzaldehyde $(\mathrm{m} / z, 210>$ 149). The specificity of the analytical measurement was shown in Fig. 8, which indicated no interference from the plasma matrices.

\section{Recovery}

The relative recovery of the analytical method, defined as the mean-peak-area ratio of methoxyamine to internal standard in the plasma standard to the mean-peak-area ratio of methoxyamine to internal standard in the aqueous reference multiplies $100 \%$, was examined. By triplicate measurements, the mean relative recoveries were $90.1,91.4$ and $94.7 \%$ at three methoxyamine levels $(5.00,50.0$ and $500 \mathrm{ng} / \mathrm{ml})$.

\section{Precision and accuracy}

The precision and accuracy of the method were determined by analyzing the plasma methoxyamine controls at three concentration levels $(5.00,50.0$ and 

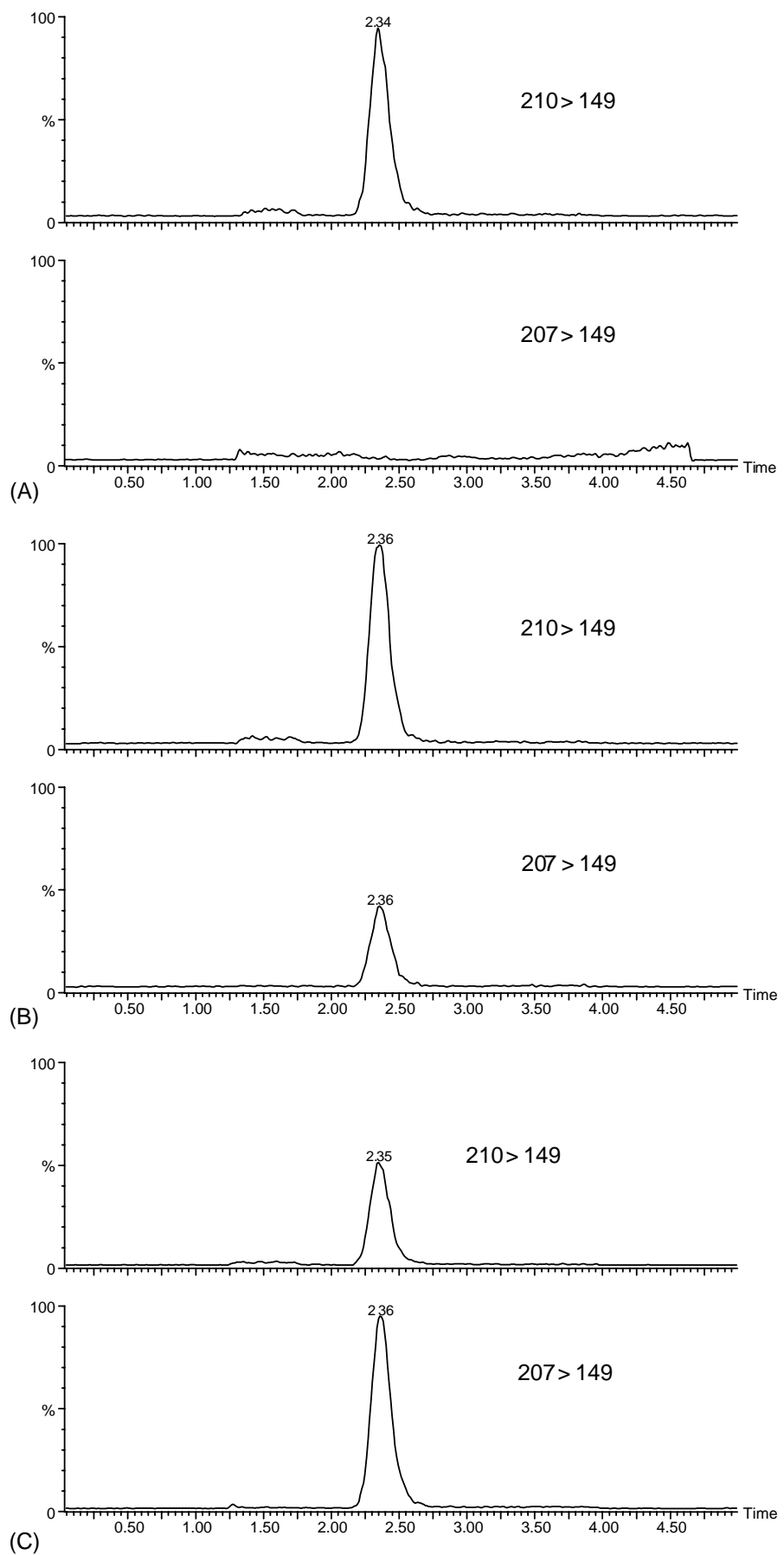

Fig. 9. The representative mass chromatograms of mouse plasma samples: (A) the pooled mouse plasma with I.S.; (B) the plasma sample collected $30 \mathrm{~min}$ after the injection with I.S. and (C) the plasma sample collected $2.5 \mathrm{~min}$ after the injection with I.S. Dosage: $2.00 \mathrm{mg}$ methoxyamine hydrochloride/kg mouse. 
$500 \mathrm{ng} / \mathrm{ml}$ ). Five and three replicates of each concentration were assayed for intra- and inter-assay precision. The precision of the measurement of methoxyamine in human plasma was shown in Table 1 . The coefficient of variations (CVs) for both intra- and inter-assay were less than $4 \%$ at the three concentration levels. The accuracy, defined as the measured value divided by the accepted value multiplies $100 \%$, were $95.0,90.1$, and $96.3 \%$ at the three concentration levels by triplicate measurements.

\section{Linearity}

The linearity of the ESI-MS-MS response for methoxyamine in human plasma was established over the concentration range of $1.00-1000 \mathrm{ng} / \mathrm{ml}$ with a correlation coefficient of 0.9999 . The mean calibration curve from three separate calibration curves made over one month of time gave a mean calibration equation $y=0.0579 x$ with a CV of $2.4 \%$ for the slope.

\section{Detection limits}

The limit of detection (LOD) and the limit of quantification (LOQ) for the method were calculated as 3 and 10 times of signal-to-noise ratio (peak-to-peak). Based on five replicate analyses of $1.00 \mathrm{ng} / \mathrm{ml}$ plasma methoxyamine calibrator, the calculated LOD and LOQ of the method were 0.150 and $0.500 \mathrm{ng} / \mathrm{ml}$, respectively.

\section{Pharmacokinetic study}

The validated method was used to determine plasma methoxyamine in mice with and without bolus injections of methoxyamine hydrochloride. After the frozen mouse plasma samples $\left(-20^{\circ} \mathrm{C}\right)$ were thawed to the room temperature, $150 \mu \mathrm{l}$ aliquots were used for the analyses according to the procedures described in Section 2, and the internal calibration curve was

Table 1

The intra- and inter-assay precision of plasma methoxyamine

\begin{tabular}{lll}
\hline $\begin{array}{l}\text { Plasma } \\
\text { methoxyamine } \\
(\mathrm{ng} / \mathrm{ml})\end{array}$ & $\begin{array}{l}\text { Intra-assay } \\
\text { precision } \\
(\mathrm{CV} \%, n=5)\end{array}$ & $\begin{array}{l}\text { Inter-assay } \\
\text { precision } \\
(\mathrm{CV} \%, n=3)\end{array}$ \\
\hline 5.00 & 2.2 & 3.7 \\
50.0 & 1.3 & 1.1 \\
500 & 1.9 & 0.49 \\
\hline
\end{tabular}

plotted. The results demonstrated that mouse plasma samples collected without injection of methoxyamine hydrochloride showed no sign of interference from endogeneous compounds, whereas plasma samples following injections of methoxyamine hydrochloride gave clear identification of methoxyamine. Representative mass chromatograms of mouse plasma samples were given in Fig. 9. The plasma methoxyamine
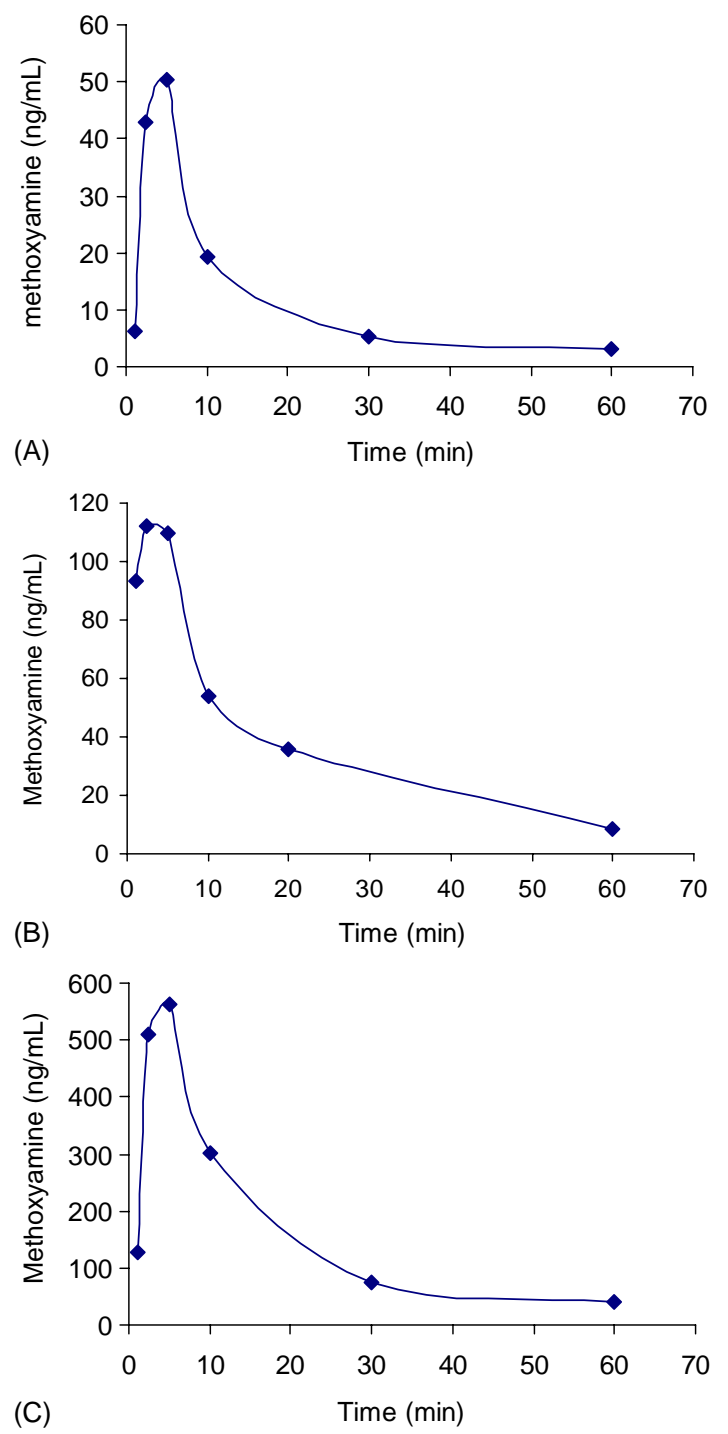

Fig. 10. The plasma methoxyamine concentration profiles in mice. Dosages: (A) $2.00 \mathrm{mg}$ methoxyamine hydrochloride/kg mouse; (B) $5.00 \mathrm{mg}$ methoxyamine hydrochloride $/ \mathrm{kg}$ mouse and (C) $20.0 \mathrm{mg}$ methoxyamine hydrochloride/kg mouse. 
Table 2

Pharmacokinetic parameters of methoxyamine

\begin{tabular}{lcll}
\hline & $2(\mathrm{mg} / \mathrm{kg})$ & $5(\mathrm{mg} / \mathrm{kg})$ & $20(\mathrm{mg} / \mathrm{kg})$ \\
\hline$T_{\max }(\min )$ & 5.00 & 2.50 & 5.00 \\
$C_{\max }(\mathrm{ng} / \mathrm{ml})$ & 50.30 & 112.00 & 562.00 \\
$\mathrm{AUC}_{\text {last }}(\mathrm{min} \mathrm{ng} / \mathrm{ml})$ & 704.82 & 2210.00 & 9535.25 \\
$T_{1 / 2}(\min )$ & 20.13 & 18.54 & 18.03 \\
\hline
\end{tabular}

profiles from mice following single bolus intraperitoneal injections of 2,5 , and $20 \mathrm{mg}$ methoxyamine hydrochloride per kilogram of mouse were shown in Fig. 10. The pharmacokinetic parameters of methoxyamine were summarized in Table 2 . The results indicate the method developed may be used to accurately determine methoxyamine in plasma samples.

\section{Conclusions}

A ESI-MS-MS with on-line sample extraction method for the quantitative determination of methoxyamine in human and mouse plasma has been developed and validated. Methoxyamine was accurately determined in plasma through its reaction with $4-(N, N-$ diethylamino)benzaldehyde under the acidic conditions. The reaction product was confirmed by fragmentation experiments. The protein-bound methoxyamine was recovered by heating at $80^{\circ} \mathrm{C}$ for $1 \mathrm{~h}$. This method was rugged and specific. It has been used to analyze plasma samples from the pharmacokinetic study in mice.

\section{References}

[1] M. Liuzzi, M. Talpeart-Borle, J. Biol. Chem. 260 (1985) 5252.

[2] S. Rosa, P. Fortini, M. Bignami, E. Dogliotti, Nucleic Acids Res. 19 (1991) 5569.

[3] M. Liuzzi, M. Weinfeld, M.C. Paterson, Biochem. 26 (1987) 3315.

[4] S.L. Gerson, L. Liu, US Pat. Appl. Publ., US2002198264 A1 (2002).

[5] S.L. Gerson, L. Liu, PCT Int. Appl., WO 2001022199 A2 (2001).

[6] L. Liu, P. Taverna, C.M. Whitacre, S. Chatterjee, S.L. Gerson, Clin. Cancer Res. 5 (1999) 2908.

[7] L. Liu, Y. Nakatsuru, S.L. Gerson, Clin. Cancer Res. 8 (2002) 2985.

[8] http://www.dtp.nci.nih.gov/docs/raid/raid_index.html.

[9] P.E. Iversen, H. Lund, Anal. Chem. 41 (1969) 1322.

[10] T.K. Korpela, M.J. Makela, Anal. Biochem. 110 (1981) 251.

[11] E. Wang, E. Struble, P. Liu, A.P. Cheung, J. Pharm. Biomed. Anal. 30 (2002) 415.

[12] V.A. Palm, Tables of Rate and Equilibrium Constants of Heterolytic Organic Reactions, vol. 2 (1), Academy of Sciences of the USSR, Moscow, 1976.

[13] M. Talpaert-Borle, M. Liuzzi, Biochim. Biophys. Acta 740 (1983) 410.

[14] J.C. Kotz, P.M. Treichel Jr., P.A. Harman, Chemistry and Chemical Reactivity, fifth ed., Thomson, Toronto, 2003, Chapter 16, p. 674.

[15] S. Yang, X. Zheng, Y. Xu, X. Zhou, J. Pharm. Biomed. Anal. 30 (2002) 781.

[16] Y. Xu, J.L. Grem, J. Chromatogr. B 783 (2003) 273. 